\title{
Wetland characteristics linked to broad-scale patterns in Culiseta melanura abundance and eastern equine encephalitis virus infection
}

\author{
Nicholas K. Skaff ${ }^{1,2^{*}}$, Philip M. Armstrong ${ }^{3}$, Theodore G. Andreadis ${ }^{3}$ and Kendra S. Cheruvelil ${ }^{1,4}$
}

\begin{abstract}
Background: Eastern equine encephalitis virus (EEEV) is an expanding mosquito-borne threat to humans and domestic animal populations in the northeastern United States. Outbreaks of EEEV are challenging to predict due to spatial and temporal uncertainty in the abundance and viral infection of Cs. melanura, the principal enzootic vector. EEEV activity may be closely linked to wetlands because they provide essential habitat for mosquito vectors and avian reservoir hosts. However, wetlands are not homogeneous and can vary by vegetation, connectivity, size, and inundation patterns. Wetlands may also have different effects on EEEV transmission depending on the assessed spatial scale. We investigated associations between wetland characteristics and Cs. melanura abundance and infection with EEEV at multiple spatial scales in Connecticut, USA.

Results: Our findings indicate that wetland vegetative characteristics have strong associations with Cs. melanura abundance. Deciduous and evergreen forested wetlands were associated with higher Cs. melanura abundance, likely because these wetlands provide suitable subterranean habitat for Cs. melanura development. In contrast, Cs. melanura abundance was negatively associated with emergent and scrub/shrub wetlands, and wetland connectivity to streams. These relationships were generally strongest at broad spatial scales. Additionally, the relationships between wetland characteristics and EEEV infection in Cs. melanura were generally weak. However, Cs. melanura abundance was strongly associated with EEEV infection, suggesting that wetland-associated changes in abundance may be indirectly linked to EEEV infection in Cs. melanura. Finally, we found that wet hydrological conditions during the transmission season and during the fall/winter preceding the transmission season were associated with higher Cs. melanura abundance and EEEV infection, indicating that wet conditions are favorable for EEEV transmission.
\end{abstract}

Conclusions: These results expand the broad-scale understanding of the effects of wetlands on EEEV transmission and help to reduce the spatial and temporal uncertainty associated with EEEV outbreaks.

Keywords: Eastern equine encephalitis virus, Wetlands, Culiseta melanura, Vegetation, Connectivity, Hydrology, Drought

\footnotetext{
*Correspondence: skaffnic@msu.edu

'Department of Fisheries and Wildlife, Michigan State University, East Lansing, MI, USA

${ }^{2}$ Ecology, Evolutionary Biology \& Behavior Program, Michigan State

University, East Lansing, MI, USA

Full list of author information is available at the end of the article
} 


\section{Background}

Eastern equine encephalitis virus (EEEV; Togaviridae, Alphavirus) is a highly pathogenic mosquito-borne zoonosis that is responsible for severe disease in humans and equines, resulting in high mortality and severe neurological impairment in most survivors [1-4]. Outbreaks of EEEV in the northeastern United States occur intermittently [2], but appear to be resurging and expanding throughout the region [3,4]. The frequency and intensity of these events are difficult to predict due to spatial and temporal uncertainty in the population abundance and viral infection rate of the primary vector species, Culiseta melanura [5-7]. Abundance and EEEV infection of Cs. melanura may be closely linked to local land cover characteristics, particularly wetland cover that provides important habitat for vectors and susceptible hosts [6, 8-10]. Therefore, increasing our understanding of wetland effects on Cs. melanura abundance and viral infection can help to identify key elements that enhance potential outbreaks.

The influence of wetlands on Cs. melanura and EEEV infection may depend on the spatial scales and temporal periods over which relationships are evaluated. The effects of wetlands may change in magnitude or direction depending on the spatial scales of analysis, and temporally dynamic drivers may have lagged effects because precursors to shifts in mosquito infection and abundance can arise months in advance $[11,12]$. The scales and lags most predictive of Cs. melanura abundance and EEEV infection may correspond with the distance and timing of vector and host movements [13]. However, uncertainty surrounding current estimates and the relative importance of vector and hosts movement necessitates evaluating the effects of wetland cover and temporallyvarying wetland conditions at a range of potential spatial scales and temporal lags $[12,14]$.

To date, knowledge of the potential impacts of wetland characteristics on EEEV transmission in the northeastern US is derived from studies using two methodologies. There are small-scale studies that focus on Cs. melanura habitat utilization in individual wetlands, but do not estimate Cs. melanura habitat utilization at broad epidemiologically relevant scales [6, 8, 15]. There are also studies evaluating Cs. melanura abundance at the broad spatial scales most relevant to pathogen spread and management. However, these studies typically aggregate wetlands of various vegetation, structural, and inundation types into just one or a few categories. This fails to account for the important differences in wetland habitats that have been identified in small-scale studies [9, 16-18]. Based on the results of these analyses, there is evidence that the specific vegetative, structural, and inundation characteristics of wetlands may have important effects on both Cs. melanura population abundance and EEEV infection at broad scales.

Wetland characteristics can influence either Cs. melanura abundance or infection with EEEV. For our analyses of Cs. melanura abundance, we focus on three wetland characteristics that may have important effects wetland vegetation, wetland connectivity, and wetland inundation classification:

(i) Wetland vegetation: Vegetation imposes important constraints on the suitability of wetland habitats to Cs. melanura larval development. Studies have found that larval Cs. melanura proliferate in freshwater forested swamps, both deciduous and evergreen, usually in recesses beneath tree-roots and other dark, thermally stable microhabitats $[8,15$, 19]. These precipitation- and groundwater-fed wetlands are dominated by red maple (Acer rubrum), Atlantic white cedar (Thuja occidentalis), yellow birch (Betula alleghaniensis), and eastern hemlock (Tsuga canadensis) [2, 10, 20]. Wetlands dominated by different vegetation types, like emergent and scrub-shrub vegetation, appear to be of minor importance as Cs. melanura larval habitats [9, 20].

(ii) Wetland connectivity: Connectivity of wetlands to other aquatic habitats may influence mosquito abundance via changes in mosquito predator dispersal. Mosquito predators typically include water-dependent taxa like amphibians, small fishes, and larval macroinvertebrate insects [20, 21]. Studies of several mosquito species, although not $C$. melanura, have found that the density and proximity of wetland habitats and the number of stream connections between aquatic environments have a positive influence on mosquito predator movement. These forms of connectivity help to stabilize predator metacommunities leading to larger predator populations and potential reductions in mosquito abundance [22-24].

(iii)Wetland inundation classification: A wetland's inundation classification (a way of categorizing wetlands based on the duration and timing of surface inundation) in conjunction with changes in hydrological wetness (water table depth) may directly or indirectly influence Cs. melanura abundance. Drying and subsequent re-inundation of semi-permanently inundated wetlands have been indirectly linked to increases in larval mosquito biomass (although not tested in Cs. melanura) via decreases in mosquito predator biomass [21]. In contrast, hydrological changes in wetlands with other inundation classifications (i.e. permanent and temporary wetlands) have limited effects on mosquito biomass [21]. Finally, increases in 
groundwater levels, leading to sustained inundation of larval habitats during the winter and transmission season, can stabilize larval habitat and directly promote larger populations of Cs. melanura $[2,6]$.

The above relationships are primarily derived from local-scale studies linking wetland characteristics and larval abundance. It is unclear whether these results apply to broad-scale patterns in adult Cs. melanura abundance or whether findings derived from other mosquito species apply to Cs. melanura.

Wetlands may also influence EEEV infection in Cs. melanura via three wetland characteristics: wetland vegetation, wetland size, and wetland inundation classification:

(i) Wetland vegetation: Wetland vegetation imposes constraints on the locations where contact between vectors and susceptible avian hosts occurs. Forest wetlands are key sources of food, water, and nesting habitat for a variety of passerine species (primary avian EEEV hosts) and support double the bird density of nearby upland sites [10]. Although recently-emerged Cs. melanura adults disperse from wetland habitats $[6,19]$, vectors will opportunistically feed on nearby hosts if they are in high densities $[25,26]$. Therefore, forested wetlands and their surroundings may be focal points for contact between susceptible passerines and Cs. melanura, leading to an increase in vector EEEV infection.

(ii) Wetland size: Wetland size may affect mosquito infection due to the positive relationship between wetland size and avian species richness ([27, 28] reviewed in [29]). Previous studies have shown that small wetlands tend to have low avian species richness and to be dominated by highly susceptible passerines, whereas large wetlands have a diverse mix of susceptible and non-susceptible birds that reduces viral amplification (though not tested in EEEV system) [27, 28].

(iii)Wetland inundation classification: A wetland's inundation classification combined with changes in hydrological wetness (water table depth) may alter host density and mosquito infection. Research on West Nile virus (WNV) and St. Louis encephalitis virus (SLEV) indicates that drought-driven reductions in water table depth reduces the availability of aquatic habitats forcing vectors and avian hosts onto a few remaining aquatic refuges [30-34]. This may result in increased contact between important vectors and hosts and subsequent increases in vector infection.

To assess the influence of broad-scale wetland characteristics on EEEV transmission, we investigated links between wetland land cover characteristics and Cs. melanura abundance and EEEV infection in Connecticut. We focus our analyses on wetlands with four vegetation types: (i) evergreen forest; (ii) deciduous forest; (iii) emergent vegetation; and (iv) scrub-shrub vegetation. We hypothesize that forested wetland habitats will be positively associated with Cs. melanura abundance and EEEV infection, and that there will be no strong relationships between emergent and scrub-shrub wetlands and both response variables.

Further, we examine several other wetland characteristics with potential influences on EEEV transmission: (i) hydrological connectivity to streams; (ii) wetland patch size; and (iii) inundation classification and hydrological wetness. We hypothesize that connectivity will have a negative relationship with abundance, and that wetland size will have a positive relationship with EEEV infection. We also expect that drought in forested semipermanent wetlands during the previous transmission season, and inundation during the winter and during an ongoing transmission season will be positively associated with Cs. melanura abundance. Further, we expect that drought during the transmission season be positively associated with EEEV infection. Finally, we examine the spatial scales over which these wetland characteristics are most important and both the spatial scales and monthly temporal lags associated with the strongest effects of wetland inundation and hydrological wetness conditions. Overall, we aim to identify landscape-level wetland effects on Cs. melanura abundance and EEEV infection, the spatial scales and temporal lags over which these effects are most important, and to ultimately help foster a better understanding of broad-scale patterns of EEEV transmission.

\section{Methods}

Mosquito trapping, identification, and viral isolation

Data were acquired across the state of Connecticut, in the northeastern United States (Fig. 1), which experienced EEEV infections in Cs. melanura in most years during the study period, 2001-2014 [35]. Mosquito trap data were collected as part of the State of Connecticut Mosquito Trapping and Arbovirus Testing Program [36, 37]. There were 91 trapping sites each year, but 97 total sites were used over the course of the entire study period because the locations of 6 traps changed over time. Traps were placed in a variety of habitat types ranging from urban to rural, and from upland to wetland habitats. They were deployed in the late morning or early afternoon and retrieved the following morning at least once every ten days. In most cases, two types of traps were used at each site, a $\mathrm{CO}_{2}$ (dry ice) - baited $\mathrm{CDC}$ miniature light trap with an aluminum dome, and a CDC gravid mosquito trap 


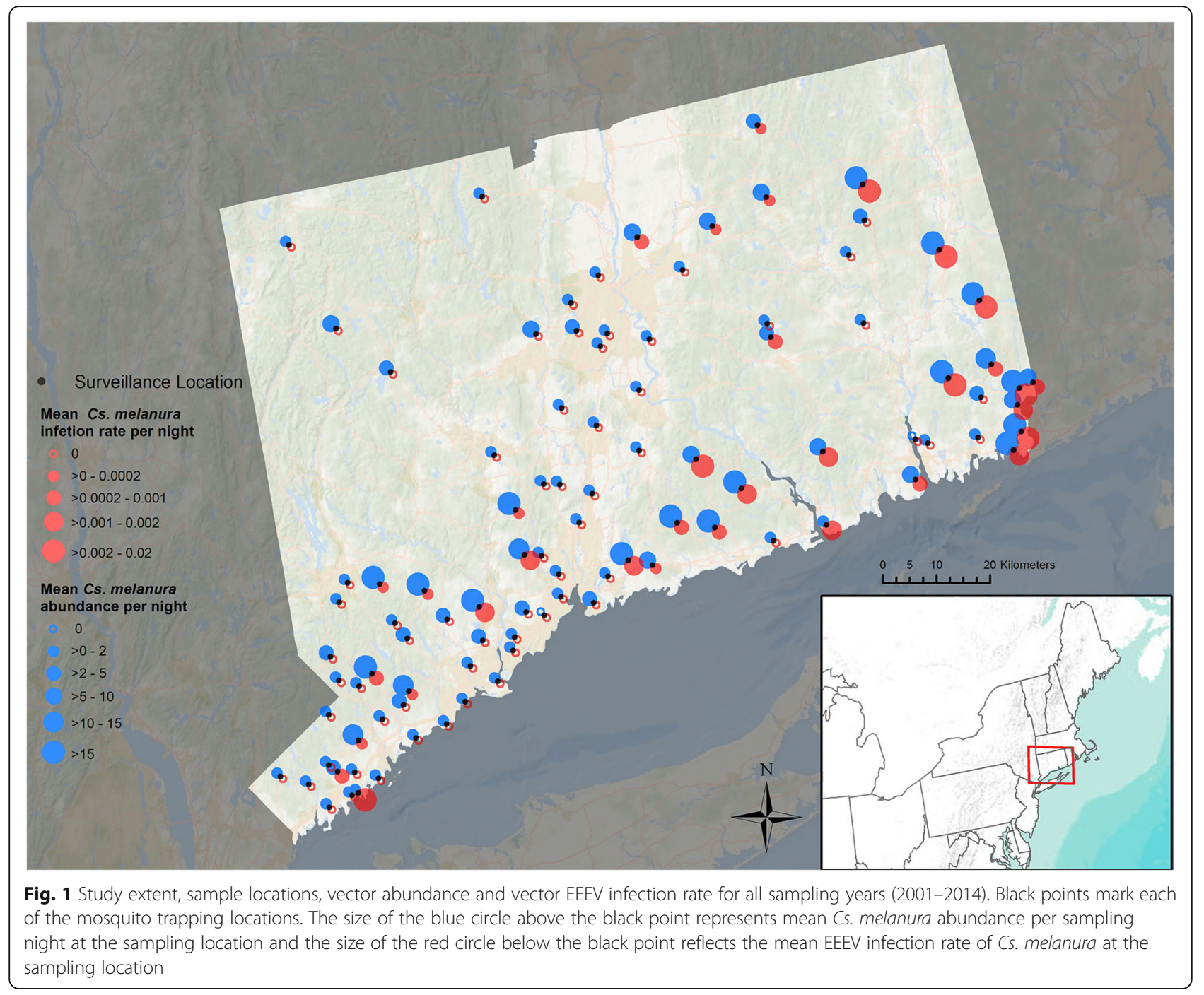

[38] baited with a rabbit chow infusion (Purina Mills LLC, St. Louis, MO, USA) [36].

Mosquitoes were identified to species and placed in pools ranging from 1 to 50 individuals. We included only Cs. melanura in our analyses, because it is the primary contributor to EEEV transmission in CT [5]. EEEV was identified from Vero cell positive cultures using either reverse transcription-polymerase chain reaction (RT-PCR) (2001) or TaqMan RT-PCR (2002-2014). Further details on sample site locations, trapping protocol, and viral isolation were previously described [36].

\section{Wetland cover data collection and processing}

Circular buffers with radii of $50 \mathrm{~m}, 100 \mathrm{~m}, 200 \mathrm{~m}$, $500 \mathrm{~m}, 750 \mathrm{~m}, 1000 \mathrm{~m}, 1500 \mathrm{~m}, 2000 \mathrm{~m}, 3000 \mathrm{~m}$, $4000 \mathrm{~m}$, and $5000 \mathrm{~m}$ were generated around each sampling site using ArcGIS 10.3.1. Using the same software, we calculated the proportion of the total buffer area covered by wetlands with the following characteristics: deciduous forest vegetation, evergreen forest vegetation, emergent vegetation, scrub/shrub vegetation, and forested wetlands with a semi-permanent inundation classification. We also calculated the average size of forested wetlands within each buffer, the average number of stream connections in forested wetlands within each buffer, and the area of forested semi-permanent wetlands relative to all other wetland types. This last variable was included in addition to the variable representing the proportional area of forested semi-permanent wetland within each buffer because it captures the effects of inundation-driven vector and host movement between wetland types.

Wetland data were acquired from geodatabases associated with LAGOS-NE $[39,40]$. In particular, these geodatabases contained wetland location, size, vegetative cover, and inundation classification data originating from the National Wetlands Inventory (NWI) [41], which holds information on all aerially visible wetlands in the 
US $(38,404$ wetlands in CT). Wetland hydrological connectivity to streams was not included in the NWI, but was calculated and made available within LAGOS-NE using ArcGIS 10.1 and the LAGOS-GIS Toolbox [39, 42]. Stream locational data were acquired from 1:24,000 scale National Hydrography Dataset (NHD) [43]. Stream connections included NHD features defined as "Stream/ River", "Canal/Ditch", "Pipeline", or "Underground Conduit" [39, 43].

The mean quantity of impervious surface land cover was also calculated within each buffer for inclusion in models to control for the effects of human development on mosquito abundance and viral infection. Impervious surface data were acquired from the 2006 version of the National Land Cover Database (NLCD) percent developed imperviousness layer [44]. We used the 2006 version because it is closest to the midpoint of our study period and is likely the closest representation of the status of impervious surfaces over the entire time-period. The percent coverage of impervious surfaces was calculated by averaging the impervious surface percent values of all the raster pixels within each buffer.

\section{Hydrological wetness conditions data collection and processing}

We quantified the monthly Palmer Hydrological Drought Index (PHDI) from 2000 to 2014 at each trapping location [45]. Because PHDI is a hydrological, rather than a meteorological measure of drought and wetness, it generally lags behind measures of precipitation and temperature and reflects groundwater levels. Therefore, it is likely a good estimate of the inundation status of the forested wetlands preferred by Cs. melanura [2]. PHDI data are available at the climate division scale, of which there are three in CT. We identified the climate division that contains each trapping site and attributed the PHDI data from that climate division to the trapping site. We then generated monthly PHDI lags by extracting PHDI data 0 to 12 months prior to the sampling month in 1-month increments (R 3.2.3).

\section{Spatial scale and monthly lag selection}

Two response variables were included in our analyses: (i) monthly mean Cs. melanura abundance per night and (ii) monthly EEEV presence/absence in Cs. melanura. Response variables were aggregated by month because individual trapping days often yielded no virus isolations and the time between individual trapping days was not always constant. We determined monthly mean Cs. melanura abundance per night by calculating the mean number of mosquitoes collected per night at each sampling site every month. This metric combines the total capture of all traps, usually a gravid trap and a light trap, operated at each site. We determined the monthly presence/absence of EEEV by evaluating whether any pools had tested positive for EEEV over the course of a month at each sampling site. We identified the monthly lags and spatial scales for each covariate that best explain variation in these response variables by adapting a previously used approach [46], which we have fully described in Additional file 1. This method allowed us to avoid: (i) making the assumption that a variable's best fitting scale or lag in a univariate model is the best scale/lag in the context of the full model and (ii) evaluating all possible combinations of scales and lags in the context of the full model, which is computationally impractical and prone to statistical error [46, 47].

\section{Analysis of wetland effects on Cs. melanura infection and abundance}

Generalized Additive Models (GAMs) were used to evaluate and visualize the relationships between the response and explanatory variables (at the best performing scales/lags) using the $m g c v$ package in $\mathrm{R}$ 3.2.3 [48]. GAMs are non-parametric models that build on Generalized Linear Models (GLMs) by loosening assumptions about the relationship between predictor and response variables. Whereas this relationship must be linear in GLMs, the only constraint in GAMs is that the relationship be smooth. GAMs include GLMs when the smoothing parameters are linear, but they also allow for non-linear relationships between predictors and response $[49,50]$. We used these models to avoid the need to pre-specify the relationship between the predictors and each response (e.g. linear, quadratic, cubic etc.), because there is little preexisting information indicating the shape of these relationships $[12,51]$. The $m g c v$ package also includes a feature that automatically penalizes the smoothing parameters associated with each predictor variable so that predictors are removed from the model if they do not improve model fit and have smoothing parameters that approach infinity [52]. This selection tool indicated that our full models were also our most parsimonious, and this was further substantiated by assessments of AIC scores during the scale/lag selection process (Additional file 1), which indicated that all covariates measured at the selected scales/lags improved AIC scores by at least 2 units. A basis dimension of 3 or 4 , corresponding to 2 or 3 degrees of freedom respectively, was used for all penalized regression smoothers to limit model over-fitting and yet accommodate parabolic and threshold relationships. The deviance explained by individual covariates was calculated using the dev.expl.mgcv package in R 3.2.3 [53].

We included additional non-wetland variables in our models in order to control for their effects. We included the percent of impervious surface coverage (many potential effects on vector and host populations), the 
month when sampling occurred (to account for withinseason temporal autocorrelation), and the number of gravid traps relative to the number of light traps ( 1 of each type was not always deployed each night). We also included the mean abundance of Cs. melanura captured per night in the EEEV infection models in order to control for the potential effect of the number of mosquitoes captured on the likelihood of EEEV detection and simultaneously to assess whether abundance influences viral amplification (although we are unable distinguish between these possibilities). Finally, we assessed several model assumptions including concurvity, the GAM equivalent of collinearity between covariates, and observed nothing problematic. We did not account for spatial autocorrelation in our models because Moran's I analyses on model residuals indicated that spatial autocorrelation was not statistically significant in any of our best performing models.

\section{Results}

\section{Mosquito collection and virus isolation}

Mosquito collection data summarized across the 13-year study period and all sampling sites are presented in Table 1. A total of 125,955 individual Cs. melanura were collected. Abundance was highest June through August, tapered off slightly in September, and was very low by October. In contrast, the proportion of EEEV positive pools was high in September and October, slightly lower in August, and near zero in June and July (Table 1). The greatest abundances of Cs. melanura were detected at sampling sites in the southern and eastern parts of Connecticut; these areas also coincided with the highest mean EEEV infection rates, with some exceptions (Fig. 1).

\section{Optimum spatial scale and temporal lag of wetland and hydrological effects}

We identified key monthly lags in hydrological wetness conditions (PHDI) and key spatial scales over which wetlands were most closely associated with Cs. melanura abundance and EEEV presence/absence. We present those results below for each response variable.

\section{Culiseta melanura abundance}

Wetland explanatory variables were most strongly associated with Cs. melanura abundance at broad spatial scales ranging from $1000 \mathrm{~m}$ to $3000 \mathrm{~m}$ from mosquito trapping sites (Fig. 2, Additional file 2: Figure S1). However, emergent wetlands had an important relationship with vector abundance at $100 \mathrm{~m}$, the second smallest spatial scale assessed (Additional file 2: Figure S1b). The relationship between human development and abundance was strongest within $200 \mathrm{~m}$ of trapping sites and progressively decreased in strength at broader spatial scales (Additional file 2: Figure S1f).

We found that changes in hydrological wetness during several time periods were important in explaining Cs. melanura abundance patterns. Hydrological wetness conditions 1 month before mosquito collection were significantly associated with Cs. melanura abundance (Fig. 2a). Hydrological wetness conditions 8 months before and during mosquito collection (0 month lag), also had strong relationships with abundance (Fig. 2b).

\section{EEEV infection in Cs. melanura}

Wetland explanatory variables also had spatial scaledependent relationships with EEEV presence/absence in Cs. melanura. Deciduous forested wetland and emergent wetlands were most strongly associated with EEEV infection at broad scales (2000-5000 m) (Additional file 3: Figure S2a, b).

The timing of hydrological conditions was also important in explaining variation in EEEV infection. Hydrological wetness 10 months prior to sampling had the strongest association with EEEV infection (Fig. 2c), however an important relationship was also detected during the month of mosquito sampling (0 month lag) (Fig. 2c).

\section{Wetland effects on Cs. melanura abundance}

The best performing GAM model explained $50.8 \%$ of the total deviance in monthly Cs. melanura abundance. Here we describe the modeled relationships between wetlands, hydrological wetness conditions, and the abundance of Cs. melanura. Full model results are presented in Table 2.

Table 1 Summary of Cs. melanura abundance and EEEV infection data. Data are aggregated across all study years (2001-2014) and all 97 sampling sites

\begin{tabular}{lllll}
\hline Month & Total captured & Mean captured/night \pm SE & \# Positive pools & \% Pools positive \\
\hline June & 30,376 & $8.66 \pm 0.38$ & 0 & - \\
July & 30,467 & $8.45 \pm 0.57$ & 2 & 0.1 \\
August & 32,563 & $7.32 \pm 0.47$ & 49 & 1.9 \\
September & 27,947 & $6.00 \pm 0.32$ & 129 & 5.2 \\
October & 6006 & $1.56 \pm 0.13$ & 41 & 3.5 \\
\hline
\end{tabular}




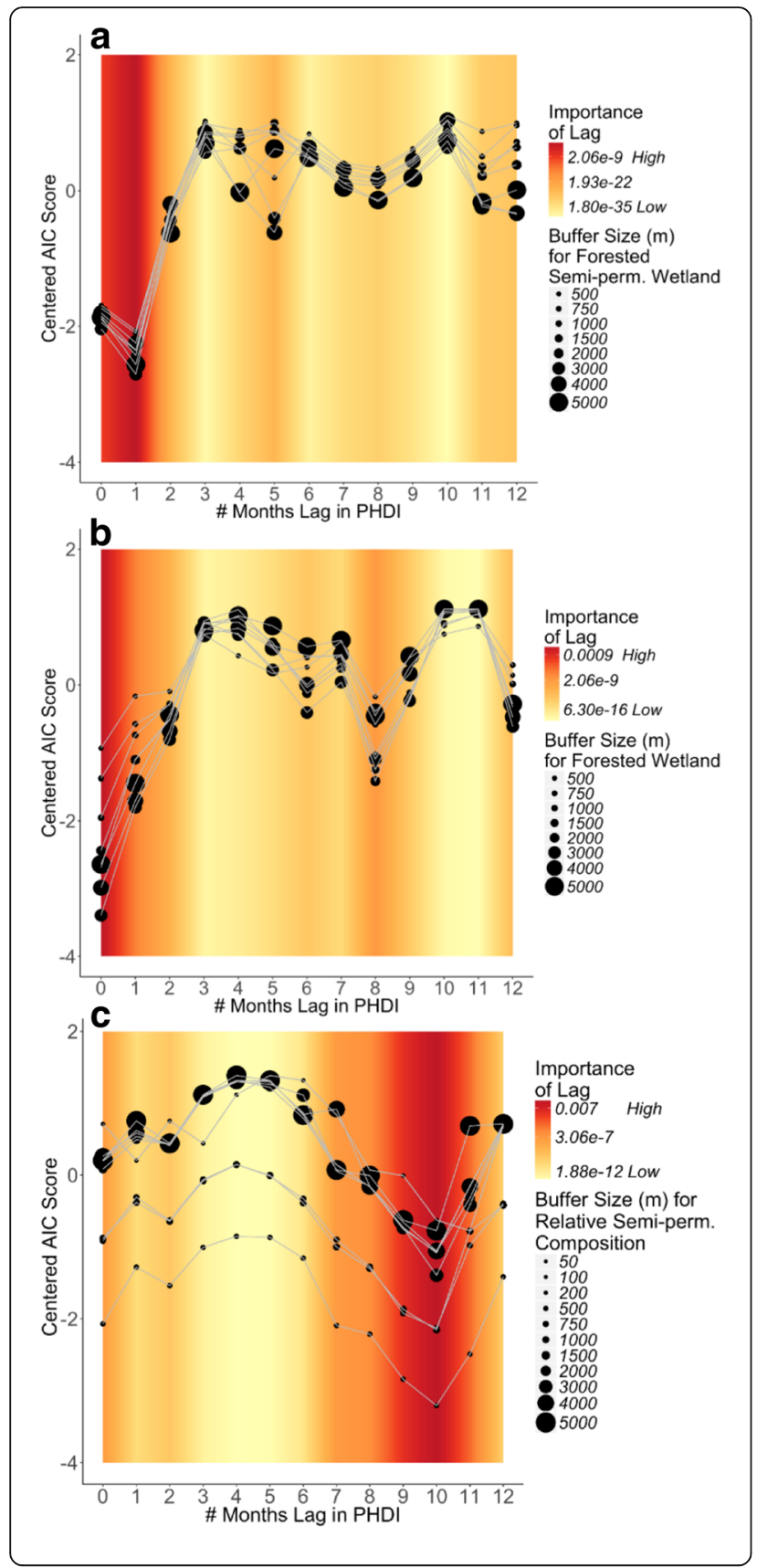

Fig. 2 Relative importance of spatial scales and temporal lags. Each plot highlights the particular monthly lags in hydrological wetness conditions (PHDI) and the spatial scales (for wetland variables) that are included in the best performing models (determined by AIC). Each black point represents a different model explaining either Cs. melanura abundance $(\mathbf{a}, \mathbf{b})$ or EEEV presence/absence $(\mathbf{c})$. Each model has a unique combination of spatial scale for the wetland variable (represented by point size) and monthly lag in hydrological conditions (PHDl; $x$-axis value). A different wetland variable is included in each plot: (a) forested semi-permanent wetlands; (b) forested wetlands; and (c) the abundance of forested semipermanent wetland relative to other wetland types. The $y$-axis lists AIC scores for each model centered on the mean AIC score of all the models. A lower centered AIC score for a model suggests better performance for that spatial scale and monthly lag combination. The background color shows the interpolated relative importance of a particular monthly lag averaged across all the models included in the plot. Red bands indicate monthly lags when hydrological conditions have the highest relative importance

\section{Wetland vegetation}

Wetland relationships with Cs. melanura abundance varied depending on wetland vegetative characteristics. Wetlands dominated by deciduous forest were associated with greater abundances of Cs. melanura at nearby mosquito trapping sites (Fig. 3a). GAM model results indicate that trapping locations surrounded by a low proportional area of deciduous wetland $(<4 \%$ of area) captured an average of less than 3 Cs. melanura individuals per night, whereas sites with the highest proportional area of deciduous wetland ( $>12 \%$ of area) captured 10 to 15 individuals (Fig. 3a). Evergreen forested wetlands were also associated with greater Cs. melanura abundance (Fig. 3b). However, the observed increase in abundance with increasing evergreen forested wetland area was less than for deciduous forested wetlands, with the expected abundance ranging from less than $2 C s$. melanura individuals per night at low levels of evergreen wetland $(<1 \%$ of area) to more than 4 individuals at the highest levels of evergreen wetland (> 8\% of area) (Fig. 3b). Emergent- and shrub-dominated wetlands, which do not serve as larval habitat for Cs. melanura, had statistically significant negative relationships with abundance (Fig. 3c, d). High proportional areas of these wetland types resulted in approximately 2 fewer Cs. melanura captured per night than in locations with few of these wetlands (Fig. 3c, d).

\section{Wetland connectivity and hydrology}

Wetland connectivity and inundation classification/ hydrological wetness were significantly associated with Cs. melanura abundance. A greater mean number of stream connections to forested wetlands was associated with a non-linear reduction in the observed abundance of Cs. melanura (Fig. 3e). No strong relationships were 
Table 2 Best-performing Generalized Additive Model (GAM) estimating Cs. melanura abundance. All explanatory variables included in the model are listed in the left-most column, including the most important spatial scale or temporal lag for that variable. The proportion of the deviance explained by each explanatory variable is listed in the right-most column. The proportion of the total deviance explained by the full model is listed in the left-most column header. For the sixth variable listed, there were two time periods when hydrological conditions were important. The variable for the second important time-period and the output values that change between models are listed in brackets

\begin{tabular}{llll}
\hline Response: Abundance (Deviance explained: 0.50) & F-score & $P$ & Deviance explained \\
\hline Emergent Wetland $100 \mathrm{~m}$ & $103.8[98.2]$ & $<0.001$ & 0.01 \\
Evergreen Forested Wetland $1000 \mathrm{~m}$ & $170.5[166.6]$ & $<0.001$ & 0.07 \\
Deciduous Forested Wetland $3000 \mathrm{~m}$ & $408.8[340.8]$ & $<0.001$ & 0.13 \\
Scrub/Shrub Wetland $3000 \mathrm{~m}$ & 94.1 & $<0.001$ & 0.02 \\
Stream Connectivity $2000 \mathrm{~m}$ & $20.3[20.5]$ & $<0.001$ & 0.01 \\
Forested Wetland $3000 \mathrm{~m}$ * PHDI (0 lag) OR [Forested Wetland 2000 m * PHDI (8 lag)] & $10.1[17.9]$ & $<0.001$ & 0.01 \\
Semi-permanent Wetland 3000 m * PHDI (1 lag) & $72.9[66.2]$ & $<0.001$ & 0.02 \\
Impervious Surfaces $200 \mathrm{~m}$ & $213.7[201.6]$ & $<0.001$ & 0.11 \\
Month & $340.5[309.75]$ & $<0.001$ & 0.07 \\
\% Gravid Traps (linear) & $-24.0[22.7](\mathrm{t})$ & $<0.001$ & 0.04
\end{tabular}

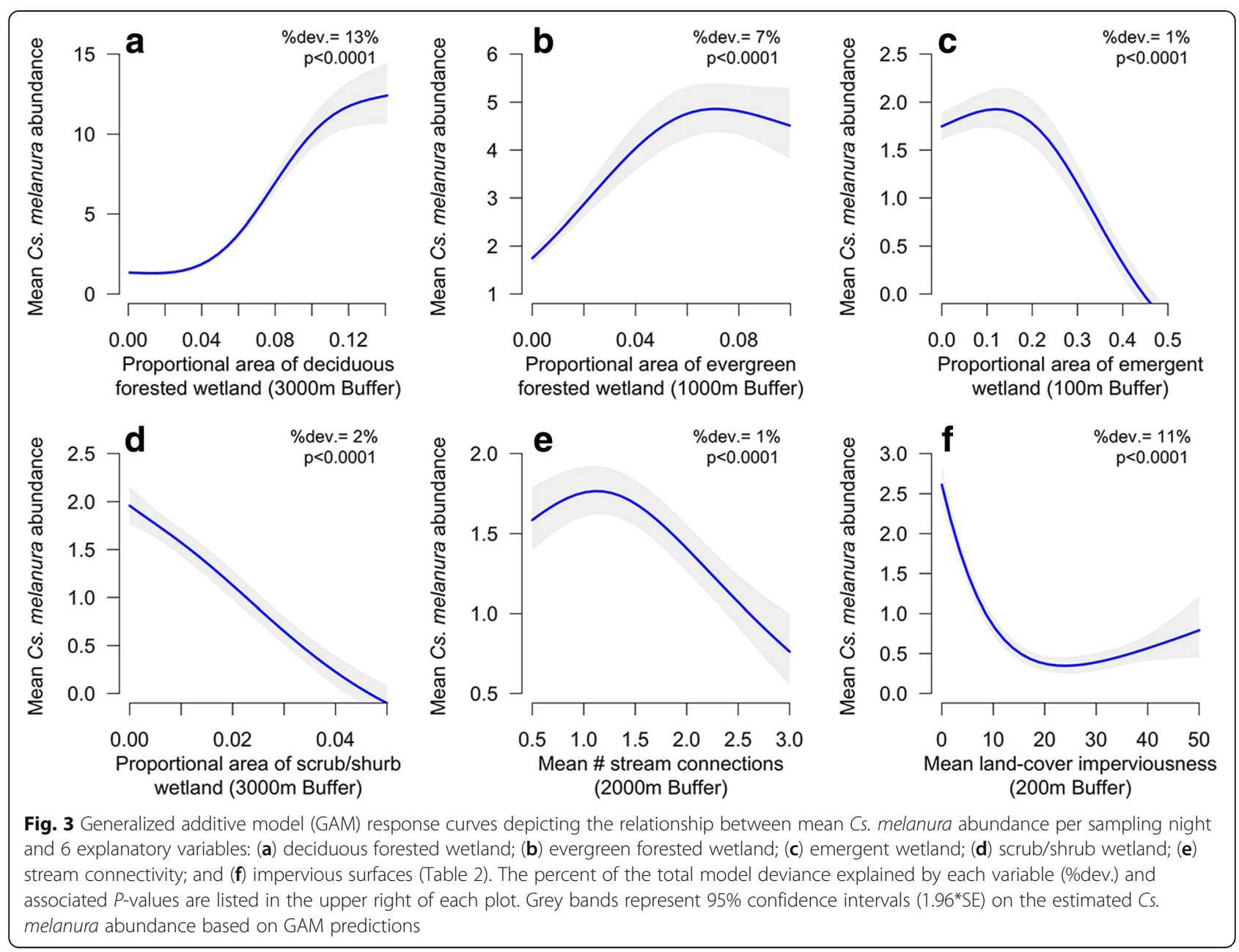



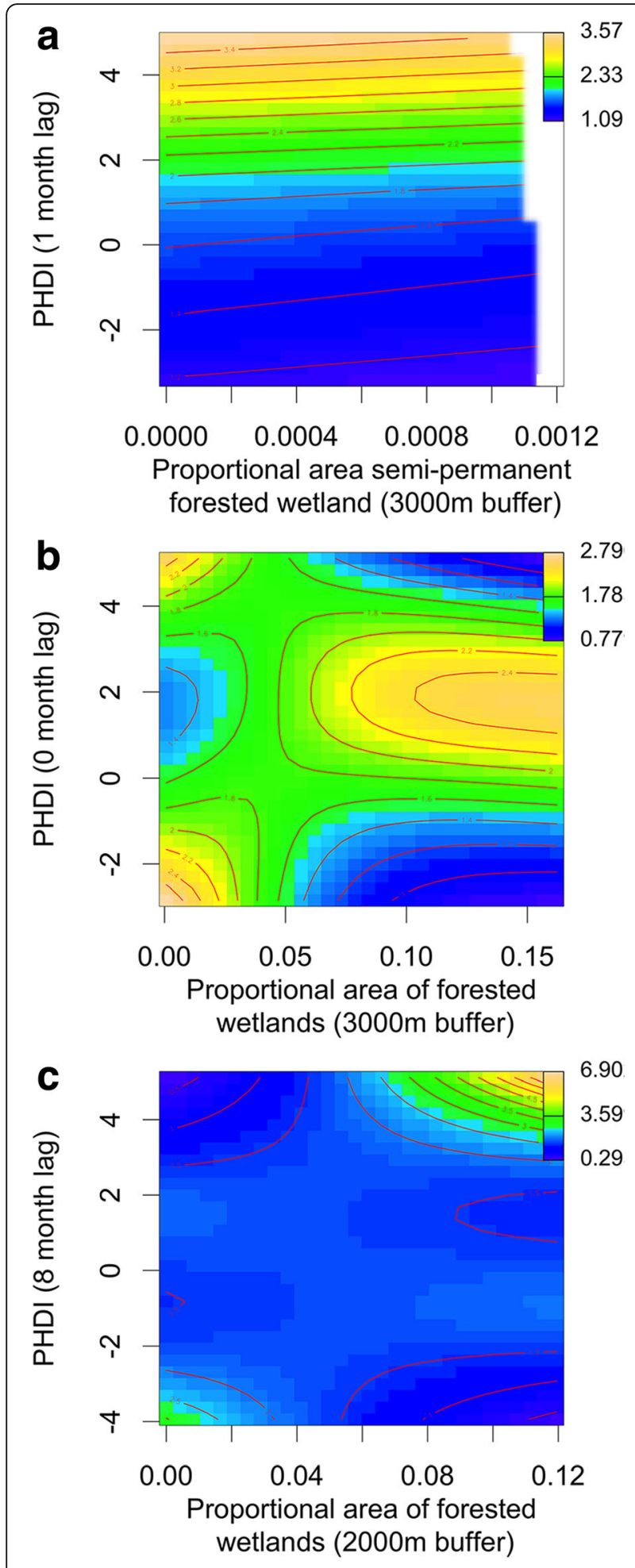

Fig. 4 Contour plots showing the effects of interactions between the proportional area of forested semi-permanent wetland (a) or all types of forested wetlands (b, c), and hydrological conditions (PHDI) on Cs. melanura abundance. (a) and (b) show this relationship during the transmission season (0-1 month lag) and (c) depicts the previous fall/winter (8 month lag). Blue represents low vector abundance and yellow represents high abundance. The range of abundance values is listed in the upper right of each plot

observed when forested wetlands were connected to fewer than 1.5 streams, but at greater levels of stream connectivity ( $\sim 3$ stream connections), vector abundance was lower ( $\sim$ individual per night) (Fig. 3e). Monthly average hydrological wetness also had significant relationships with Cs. melanura abundance (Fig. 4). Moderate to very wet hydrological conditions (PHDI > 1) 1 month before mosquito sampling were associated with greater vector abundances, regardless of semipermanent forested wetland area (Fig. 4a). Dry (PHDI < -1 ) and extremely wet conditions (PHDI $>4$ ) during the sampling month (0 month lag) in conjunction with a large quantity of forested wetlands were also associated with lower vector abundance, whereas moderately wet conditions ( 1-3 PHDI) combined with forested wetlands were associated with higher abundance (Fig. 4b). Finally, extremely wet hydrological conditions (PHDI > 4) 8 months before mosquito sampling were associated with greater vector abundances, but only when all types of forested wetland were at their highest levels (> 10\% of area) (Fig. 4c).

\section{Wetland effects on EEEV infection in Cs. melanura}

The best performing GAM model explained $49.3 \%$ of the total deviance in EEEV presence/absence. Here we describe wetland vegetation, size and inundation/hydrological wetness relationships with the log odds of EEEV presence in Cs. melanura. Detailed model results are available in Table 3.

\section{Wetland vegetation}

Several wetland vegetative characteristics were associated with changes in the log odds of EEEV presence. However, the relationships between wetland vegetation and EEEV infection were weak relative to vegetation associations with Cs. melanura abundance. Wetlands dominated by deciduous forest had a nearly linear $(e d f=0.83)$ positive association with the log odds of EEEV presence (Fig. 5a). Additionally, the proportional area of emergent wetlands had a weak but statistically significant negative association with the log odds of EEEV presence (Fig. 5c). Evergreen forested wetlands and scrub-shrub wetlands did not have statistically significant relationships with EEEV infection (Fig. 5b, d). 
Table 3 Best-performing Generalized Additive Model (GAM) estimating EEEV presence/absence in Cs. melanura. All explanatory variables included in the model are listed in the left-most column, including the most important spatial scale or temporal lag for that variable. The proportion of the deviance explained by each explanatory variable is listed in the right-most column. The proportion of the total deviance explained by the full model is listed in the left-most column header. For the sixth variable listed, there were two time periods when hydrological conditions were important. The variable for the second important time-period and the output values that change between models are listed in brackets

\begin{tabular}{|c|c|c|c|}
\hline Response: EEEV Pres/Abs (Deviance explained: 0.49 [0.46]) & $x^{2}$ & $P$ & Deviance explainec \\
\hline Emergent Wetland $2000 \mathrm{~m}$ & $8.2[4.6]$ & $0.01[0.06]^{*}$ & 0.01 \\
\hline Evergreen Forested Wetland $1000 \mathrm{~m}$ & $0[1.4]$ & $0.3[0.1]$ & 0 \\
\hline Deciduous Forested Wetland $5000 \mathrm{~m}$ & $6.1[15.6]$ & $0.005[<0.001]^{*}$ & $0.03[0.01]$ \\
\hline Scrub/Shrub Wetland 5000 m & $0[0]$ & $0.8[1]$ & 0 \\
\hline Average Forested Wetland Size 1500 m & $2.1[0.01]$ & $0.08[0.2]$ & $0.01[0.02]$ \\
\hline $\begin{array}{l}\text { Relative semi-permanent wetland } 500 \mathrm{~m}^{*} \mathrm{PHDI}(10 \mathrm{lag}) \text { OR } \\
\text { [Relative semi-permanent wetland } 500 \mathrm{~m} \text { * PHDI }(0 \mathrm{lag}) \text { ] }\end{array}$ & $43.5[24.7]$ & $<0.001^{*}$ & 0.06 \\
\hline Impervious Surfaces 200 m & $3.7[3.9]$ & $0.1[0.1]$ & 0.01 \\
\hline Month & $50.1[51.6]$ & $<0.001^{*}$ & 0.17 \\
\hline Mean Cs. melanura abundance & $70.9[53.8]$ & $<0.001^{*}$ & 0.15 \\
\hline \% Gravid Traps (linear) & $-4.3[-4.7](z)$ & $<0.001^{*}$ & 0.05 \\
\hline
\end{tabular}

${ }^{*} P<0.05$

\section{Wetland size and hydrology}

We found no statistically significant relationship between average forested wetland size and the log odds of EEEV presence (Fig. 5e). Moderately wet hydrological conditions ( 1-3 PHDI) were linked with a higher log odds of EEEV presence during two separate time periods, 10 months before (Fig. 6a) and during mosquito sampling (0 month lag) (Fig. 6b). During these same time periods, dry hydrological wetness conditions (PHDI < -1) and very wet hydrological conditions (PHDI > 3) were associated with lower log odds of infection (Fig. 6a, b). These relationships were independent of the relative area of semi-permanent forested wetland (Fig. 6a, b).

\section{Discussion}

Our aim was to identify broad-scale relationships between wetland characteristics and Cs. melanura abundance and infection with EEEV and the spatial scales and temporal periods over which these relationships are most important. Based on our spatial scale analysis, we conclude that the risks of EEEV transmission are spatially widespread, extending several kilometers from wetland habitats. Further, wetland vegetative characteristics had strong links with Cs. melanura abundance and weaker but significant associations with EEEV infection. Analyses of hydrologic and anthropogenic variables' indicate that EEEV transmission may be severe in rural areas and when hydrological conditions are particularly wet during the summer transmission season and during the fall/winter before the transmission season. Overall, these results expand the local-scale understanding of the relationships between wetland characteristics and EEEV transmission to broad scales that more closely align with landscape-wide patterns in epizootic EEEV activity.

\section{Importance of spatial scales and temporal lags}

We found that relationships between wetland characteristics and both vector abundance and EEEV infection varied depending on the spatial scale at which wetlands were measured. The strongest relationships for both response variables were generally detected when wetland characteristics were quantified at broad spatial scales with buffer radii ranging between $1000 \mathrm{~m}$ and $5000 \mathrm{~m}$. Vector abundance may be most closely linked to broadscale wetland characteristics because of the strong dispersal capabilities of Cs. melanura. Nulliparous female Cs. melanura readily disperse from larval habitats to upland areas [54] and have an estimated mean dispersal distance ranging from $4000 \mathrm{~m}$ to $9000 \mathrm{~m}$ [55]. In contrast, broad scale wetland characteristics may be important predictors of EEEV infection due to strong vector dispersal and the extensive movements of important blood hosts of Cs. melanura like the house sparrow and American robin [56] that frequently travel 1000-2000 m to nesting sites and foraging sites [57-60].

There were also several discrete time periods when hydrological conditions had important associations with both Cs. melanura abundance and EEEV infection. These time periods included the transmission season (0-1 months before the sampling month) and the fall/ winter before the transmission season (8 or 10 months before sampling month). Hydrological conditions during these periods may influence both vector abundance and EEEV infection as a result of associated changes in the availability/suitability of Cs. melanura larval habitat, 


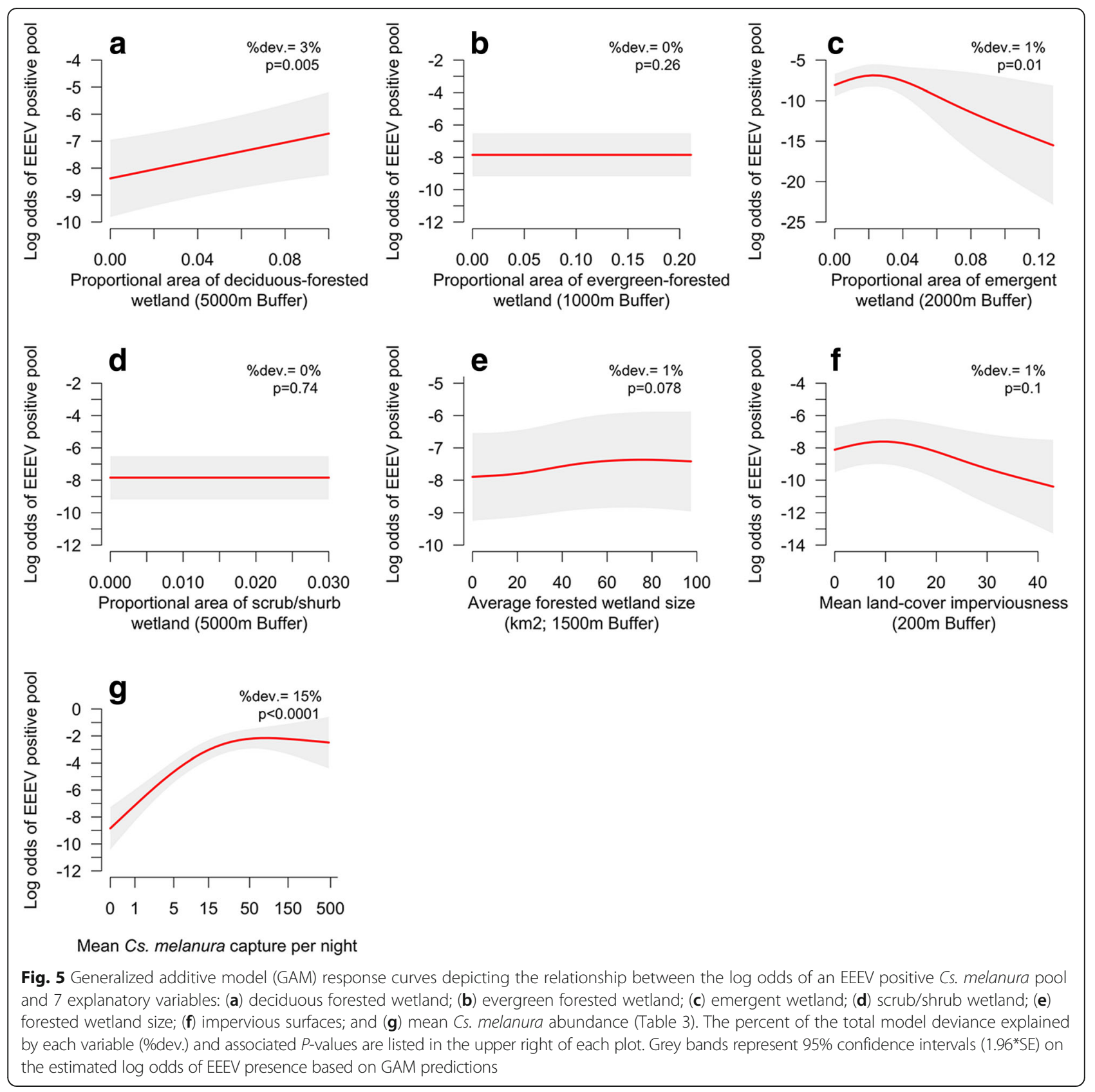

passerine habitat, and resulting contact between these taxa (see below for details) [21, 30-33].

\section{Wetland characteristics and Cs. melanura abundance}

Our analysis revealed linkages between wetland vegetative and connectivity characteristics and Cs. melanura abundance. Of the wetland vegetative factors assessed, forested deciduous and forested evergreen wetlands were most strongly associated with Cs. melanura abundance and together explained $20 \%$ of the total deviance in Cs. melanura abundance. This result closely aligns with previous fine-scale research indicating that larval Cs. melanura proliferate in forested swamps $[8,15,19]$. Deciduous forested wetland explained a greater proportion of the model deviance and increases in the quantity of this wetland type were associated with more drastic increases in Cs. melanura abundance as compared to evergreen forested wetland. This result indicates that deciduous wetland may be a more important source of larval habitat in Connecticut.

Further, forested deciduous and evergreen wetlands exhibited a non-linear relationship with Cs. melanura abundance. The sigmoid shape of the deciduous wetland vs abundance response curve (Fig. 3a) indicates that there is minimum quantity of deciduous wetland before 


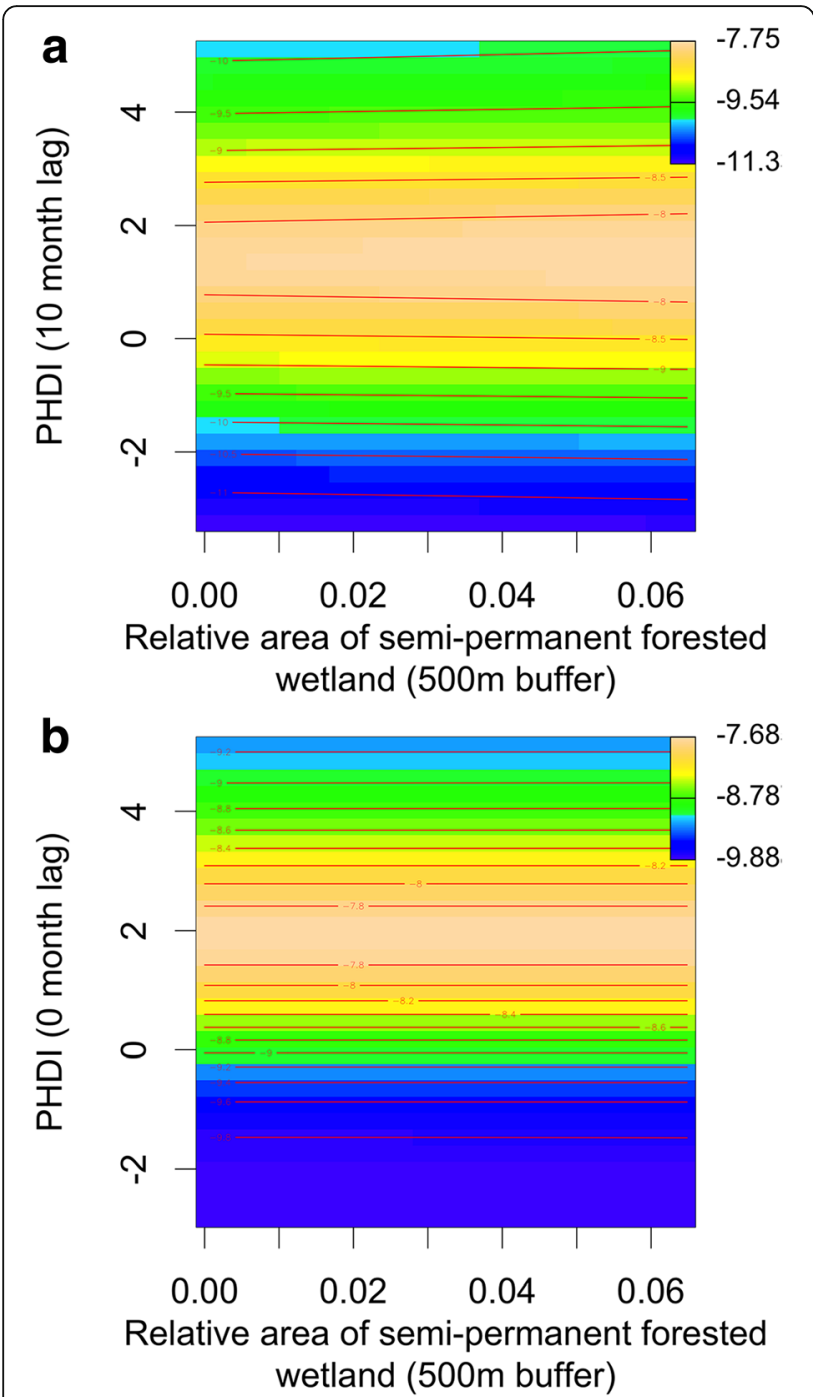

Fig. 6 Contour plots showing the effects of interactions between the relative area of semi-permanent wetland and hydrological conditions (PHDI) on the log odds of an EEEV positive Cs. melanura pool. (a) shows this relationship during the previous fall/winter (10 month lag) and (b) depicts the relationship during the transmission season (0 month lag). Blue represents low log odds of EEEV presence, yellow represents high log odds of EEEV presence, and the value range is listed in the upper right of both plots

changes in abundance can be detected ( $4 \%$ of land cover), and that there is a threshold after which additional increases in deciduous forested wetland results in little detectable change in abundance $(\sim 12 \%$ of land cover) at the $3000 \mathrm{~m}$ scale. The threshold relationship between evergreen wetlands and abundance (Fig. 3b) also indicates that there may be minimal additional positive effects on abundance once evergreen forested wetland covers more than $\sim 7 \%$ of landscape at the $1000 \mathrm{~m}$ scale. The minimum threshold for deciduous wetland likely reflects issues with detectability of low
Cs. melanura abundances at relatively broad spatial scales $(3000 \mathrm{~m})$. The maximum thresholds for both forested wetland types may indicate that female $C s$. melanura disperse greater distances for host seeking when abundance is high, thus reducing local densities [6]. These broad scale thresholds are important because vector density may reflect epizootic EEEV risks [19].

Several other wetland factors were also associated with Cs. melanura abundance. The proportional area of emergent wetlands, scrub-shrub wetlands, and the number of stream connections in forested wetlands all had statistically significant negative relationships with abundance (Fig. 3c-e). Each of these factors may have a negative relationship with abundance because they can facilitate the dispersal of mosquito predators like larval amphibians, small fishes, and larval macroinvertebrate insects to nearby forested Cs. melanura habitats [20, 21]. However, these wetland characteristics only explained $\sim 4 \%$ of the total model deviance, and there is limited field research substantiating the observed relationships with Cs. melanura abundance. Therefore, we cannot confirm that predator movement between aquatic habitats has an ecologically meaningful effect on Cs. melanura abundance. Further research is needed to examine the spatial and temporal distribution of Cs. melanura predators and how these patterns influence Cs. melanura habitat selection and abundance.

\section{Wetland characteristics and EEEV infection in Cs. melanura} Wetland characteristics were also associated with EEEV infection in Cs. melanura, although wetland variables altogether explained only $11 \%$ of the total model deviance. Deciduous wetland had a linear positive relationship with EEEV infection in Cs. melanura (Fig. 5a). This indicates that forested wetlands may be focal points for transmission because they attract high densities of birds, including a variety of susceptible passerines, to Cs. melanura larval habitat containing abundant sources of food, water, and nesting habitat [10]. Evergreen, emergent vegetation, scrub-shrub vegetation, and the size of forested wetlands had either non-significant or very weak relationships with EEEV infection in Cs. melanura (Fig. 5b-e, Table 3).

Although direct links between wetlands and EEEV infection appear to be weak, indirect links may be substantial. We found that Cs. melanura abundance had a strong positive non-linear relationship with EEEV infection and was one of the most important explanatory variables (Fig. 5g). As detailed in the previous section, wetland vegetation strongly influenced vector abundance. Therefore, there may be important indirect effects of wetland vegetation on EEEV infection due to changes in Cs. melanura abundance. The threshold 
detected (Fig. 5g) suggests that positive effects of Cs. melanura abundance on EEEV infection may taper off when mean capture reaches around 15 individuals per night and that abundances of Cs. melanura above this level may not promote more intense viral amplification. However, we cannot rule out that associations between Cs. melanura abundance and EEEV infection are related to increases in the likelihood of detecting EEEV in mosquito pools rather than real changes in EEEV infection rates. Nevertheless, previous studies have concluded that Cs. melanura abundance is in fact a key facet in determining the risk of epizootic EEEV activity [19, 61]. It would be valuable for future studies to evaluate the effects wetlands on EEEV infection rates in Cs. melanura rather than EEEV presence/absence, in order to account for the effect of abundance on the likelihood of detecting EEEV. Future studies would also benefit from better estimates of the distribution and abundance of key EEEV avian hosts, in order to identify the habitats where contact between vectors and hosts is most likely to occur.

\section{Broader hydrological and anthropogenic context of EEEV transmission}

Our models examined temporal changes in hydrological wetness conditions (measured via PHDI), how this factor interacts with the wetland inundation classification, and the resulting changes in Cs. melanura abundance and infection with EEEV. Findings indicate that when inundation levels are high in forested wetlands during the transmission season, there is likely a greater quantity of available larval habitat and vector abundance increases. Summer inundation of forested wetlands has been previously linked to increases in Cs. melanura abundance [6]. Our results also suggest that fall/winter precipitation improves Cs. melanura overwintering survival in subterranean crypts where above and below-ground water levels are influenced by water table depth $[2,11]$. In contrast, we found that hydrological conditions were not important when forested wetland was rare (Fig. 4b, c), suggesting that groundwater conditions have less influence on the availability of Cs. melanura habitat in upland locations or in wetlands with other vegetative characteristics.

Relationships between hydrological wetness and EEEV infection were independent of the relative area of semipermanent forested wetland (Fig. 6a, b). Consequently, we conclude that the contraction of wetland area during drought does not result in increased contact between vectors and hosts as observed for West Nile virus and St. Louis encephalitis virus in Florida [30-33]. Instead, we hypothesize that wet conditions during the fall/winter and during the transmission season promote the proliferation of available food, nesting resources, or an expansion of home ranges for susceptible-bird species and may increase brood size or offspring survival, leading to an influx of immunologically naïve fledglings that facilitate viral amplification [62, 63]. Moderately wet fall/ winter hydrological conditions may also be important for EEEV infection because they may improve the survival of altricial birds, including passerines [64, 65]. However, it appears that extremely wet conditions are associated with lower EEEV infection, which could be related to documented declines in passerine recruitment and parental survival when conditions are very wet $[63$, $66,67]$. Future studies should examine how wet conditions influence tradeoffs between the positive effects of more food resources on avian recruitment and the negative influence of rainfall on parental nest visitation.

The importance of the effects of wetland characteristics on Cs. melanura abundance is shaped by the level of local-scale human development (200 m from sampling location). We identified sharp decreases in Cs. melanura abundance as local urbanization increased from nearly no human development (0\% impervious surfaces) to $20 \%$ coverage with impervious surfaces (Fig. 3f) - a level of development associated with a mix of lawns, aesthetic vegetation, and large-lot residential housing [68]. When the percentage of impervious surface coverage was greater than $20 \%$, further urbanization had minimal effects on Cs. melanura abundance (Fig. 3f). These relationships were independent of nearby wetland characteristics. This indicates that even when there are forested wetlands in anthropogenic settings, including locations with dense residential housing, fewer Cs. melanura will be present than in comparable rural settings. Anthropogenic development did not have a significant relationship with EEEV infection. Therefore, susceptible avian hosts likely do not show strong preferences for rural or developed habitats, but risks of epizootic EEEV transmission may still be highest in rural locations near wetlands where Cs. melanura is most abundant.

\section{Conclusions}

Overall, wetland characteristics, particularly wetland vegetation, were important in determining spatial patterns in Cs. melanura abundance and, to a lesser extent, Cs. melanura EEEV infection. Additionally, our identification of the key spatial scales and temporal lags influencing Cs. melanura abundance and EEEV infection highlights the importance and utility of explicit evaluations of scale and timing for understanding mosquito-borne disease transmission. Future studies should also quantify wetland characteristics at broad scales and at multiple time periods to more precisely identify the location and timing of EEEV outbreaks within the northeastern US. 


\section{Additional files}

Additional file 1: Method of spatial scale and temporal lag selection. (DOCX $123 \mathrm{~kb}$ )

Additional file 2: Figure S1. Relative importance of spatial scales from $50 \mathrm{~m}$ to $5000 \mathrm{~m}$ for a mean number of stream connections to forested wetlands, $\mathbf{b}$ proportional area of emergent wetland, c proportional area of deciduous forested wetland, $\mathbf{d}$ proportional area of evergreen forested wetland, e proportional area of scrub/shrub wetland and $\mathbf{f}$ mean impervious surface coverage. Each point represents a different model explaining Cs. melanura abundance. The $y$-axis lists AIC scores for each model centered on the mean AIC score of all the models. A lower centered AIC score for a model suggests better performance for that spatial scale. The background color shows the interpolated relative importance of a particular spatial scale averaged across all the models included in the plot. Red bands indicate spatial scales where the explanatory variable has the highest relative importance. (DOCX 2196 kb)

Additional file 3: Figure S2. Relative importance of spatial scales from $50 \mathrm{~m}$ to $5000 \mathrm{~m}$ for a proportional area of deciduous forested wetland, and $\mathbf{b}$ proportional area of emergent wetland (only statistically significant explanatory variables included). Each point represents a different model explaining the presence/absence of EEEV infection in Cs. melanura. The $y$-axis lists AIC scores for each model centered on the mean AIC score of all the models. A lower centered AIC score for a model suggests better performance for that spatial scale. The background color shows the interpolated relative importance of a particular spatial scale averaged across all the models included in the plot. Red bands indicate spatial scales where the explanatory variable has the highest relative importance. (DOCX 709 kb)

\section{Abbreviations}

EEEV: Eastern equine encephalitis virus; GAMs: Generalized Additive Models; NHD: National Hydrography Dataset; NLCD: National Land Cover Database; NWI: National Wetlands Inventory; PHDI: Palmer Hydrological Drought Index; SLEV: St. Louis encephalitis virus; WNV: West Nile virus

\section{Acknowledgements}

We thank members of the Data-Intensive Landscape Limnology Lab at Michigan State University and Drs. Jean-Francois Lapierre, Emi Fergus, and Sarah Collins for reviews of early drafts that greatly improved the manuscript. We also thank John Shepard, Michael Thomas, Angela Bransfield, and Michael Misencik for their technical assistance and the many individuals involved with collecting, identifying and processing mosquitoes for virus testing at the Connecticut Agricultural Experiment Station. This research was developed under STAR Fellowship Assistance Agreement no. FP-91778301-0 awarded by the U.S. Environmental Protection Agency (EPA). It has not been formally reviewed by the EPA and the views expressed in this publication are solely those of the authors. Assistance was also provided by the NSF Graduate Research Fellowship Program, the GLEON Fellowship Program, the Ambrose Pattullo Fund for Environmental Issues Graduate Fellowship in Literary Work, the Kellogg Biological Station Graduate School Fellowship, the MSU ESPP program, and the NSF MacroSystems Biology Program in the Emerging Frontiers Division of the Biological Sciences Directorate (EF-1065786).

\section{Funding}

STAR Fellowship Assistance Agreement no. FP-91778301-0 awarded by the U.S. Environmental Protection Agency (EPA) provided funding to support NKS tuition and living expenses. NSF Graduate Research Fellowship Program provided funding to support NKS tuition and living expenses. GLEON Fellowship Program provided technical training to NKS. Ambrose Pattullo Fund for Environmental Issues Graduate Fellowship in Literary Work provided funding to support NKS living expenses. Kellogg Biological Station Graduate School Fellowship provided funding to support NKS tuition and living expenses. MSU ESPP Recruiting Fellowship provided funding to support NKS tuition and living expenses. NSF MacroSystems Biology Program in the Emerging Frontiers Division of the Biological Sciences Directorate (EF-1065786) provided funding for collection and processing of wetland data and salary support for KSC.

\section{Availability of data and materials}

The data used in this study are available from the Knowledge Network for Biocomplexity (KNB): Skaff NK, Armstrong PM, Andreadis TG, Cheruvelil KS. 2017. Wetlands and drought linked to CS. melanura abundance and infection with Eastern Equine encephalitis virus in Connecticut, USA, 2001-2014. Knowledge Network for Biocomplexity. The code used to generate the results is publically available on GitHub: Skaff NK.

Skaff_et_al_2017_EEEV_Cs_melanura. (2017). GitHub repository: https:// github.com/nskaff/Skaff_et_al_2017_EEEV_Cs_melanura.

\section{Authors' contributions}

All authors were involved in developing research questions and methods. NKS performed statistical analysis. All authors helped to interpret results and contributed to writing the manuscript. All authors read and approved the final manuscript.

Ethics approval and consent to participate

Not applicable.

\section{Consent for publication}

Not applicable.

\section{Competing interests}

The authors declare that they have no competing interests.

\section{Publisher's Note}

Springer Nature remains neutral with regard to jurisdictional claims in published maps and institutional affiliations.

\section{Author details}

${ }^{1}$ Department of Fisheries and Wildlife, Michigan State University, East Lansing, MI, USA. ${ }^{2}$ Ecology, Evolutionary Biology \& Behavior Program, Michigan State University, East Lansing, MI, USA. ${ }^{3}$ Department of Environmental Sciences, The Connecticut Agricultural Experiment Station, New Haven, CT, USA. ${ }^{4}$ Lyman Briggs College, Michigan State University, East Lansing, MI, USA.

Received: 18 May 2017 Accepted: 13 October 2017

Published online: 18 October 2017

\section{References}

1. Scott TW, Weaver SC. Eastern equine encephalomyelitis virus: epidemiology and evolution of mosquito transmission. Adv Virus Res. 1989;37:277-328.

2. Komar N, Spielman A. Emergence of eastern encephalitis in Massachusetts. Ann N Y Acad Sci. 1994;740(1):157-68.

3. Gibney KB, Robinson S, Mutebi J-P, Hoenig DE, Bernier BJ, Webber L, et al. Eastern equine encephalitis: an emerging arboviral disease threat, Maine, 2009. Vector Borne Zoonot. 2011;11(6):637-9.

4. Armstrong PM, Andreadis TG. Eastern equine encephalitis virus-old enemy, new threat. N Engl J Med. 2013;368(18):1670-3.

5. Armstrong PM, Andreadis TG. Eastern equine encephalitis virus in mosquitoes and their role as bridge vectors. Emerg Infect Dis. 2010;16(12):1869-74.

6. Howard J, Morris C, Emord D, Grayson M. Epizootiology of eastern equine encephalitis virus in upstate New York, USA. VII. Virus surveillance 1978-85, description of 1983 outbreak, and series conclusions. Emerg Infect Dis. 1988;25(6):501-14.

7. Wallis RC, Howard JJ, Main AJ Jr, Frazier C, Hayes C. An increase of Culiseta melanura coinciding with an epizootic of eastern equine encephalitis in Connecticut. Mosq News. 1974;34(1):63-5.

8. Andreadis TG, Shepard JJ, Thomas MC. Field observations on the overwintering ecology of Culiseta melanura in the northeastern USA. J Am Mosq Control Assoc. 2012;28(4):286-91.

9. Diuk-Wasser MA, Brown HE, Andreadis TG, Fish D. Modeling the spatial distribution of mosquito vectors for West Nile virus in Connecticut. USA Vector Borne Zoonot. 2006;6(3):283-95.

10. Laderman AD, Brody M, Pendleton E. The ecology of Atlantic white cedar wetlands: a community profile. Biol Rep US Fish Wildl Serv. 1989:85(7.21):1-114.

11. Hayes RO, Hess AD. Climatological conditions associated with outbreaks of eastern encephalitis. Am J Trop Med Hyg. 1964;13(6):851-8. 
12. Lafferty KD. The ecology of climate change and infectious diseases. Ecology. 2009;90(4):888-900.

13. Goodwin B, Fahrig L. Spatial scaling and animal population dynamics. Ecological scale: theory and application. New York: Columbia University Press; 1998.

14. Cohen JM, Civitello DJ, Brace AJ, Feichtinger EM, Ortega CN, Richardson JC, et al. Spatial scale modulates the strength of ecological processes driving disease distributions. Proc Natl Acad Sci USA. 2016;113(24):E3359-E64.

15. Morris C, Zimmerman R, Magnarelli L. The bionomics of Culiseta melanura and Culiseta morsitans dyari in central New York state (Diptera: Culicidae). Ann Entomol Soc Am. 1976;69(1):101-5.

16. Meentemeyer RK, Haas SE, Václavík T. Landscape epidemiology of emerging infectious diseases in natural and human-altered ecosystems. Annu Rev Phytopathol. 2012;50:379-402.

17. White C. Temporal analysis and spatial modeling of the distribution and abundance of Cs. melanura, Eastern equine encephalitis vector: Connecticut, 1997-2012. Master's thesis. University of Arizona; 2016.

18. Rochlin I, Harding K, Ginsberg H, Campbell S. Comparative analysis of distribution and abundance of West Nile and eastern equine encephalomyelitis virus vectors in Suffolk County, New York, using human population density and land use/cover data. J Med Entomol. 2008;45(3):563-71.

19. Joseph SR, Bickley WE. Culiseta melanura (Coquillett) on the eastern shore of Maryland (Diptera: Culicidae). Univ Md Agr Exp Sta Bull. 1969:A-161:1-84.

20. Rey JR, Walton WE, Wolfe RJ, Connelly CR, O'Connell SM, Berg J, et al. North American wetlands and mosquito control. Int J Environ Res Public Health. 2012;9(12):4537-605.

21. Chase JM, Knight TM. Drought-induced mosquito outbreaks in wetlands. Ecol Lett. 2003;6(11):1017-24.

22. Chase JM, Shulman RS. Wetland isolation facilitates larval mosquito density through the reduction of predators. Ecol Entomol. 2009;34(6):741-7.

23. Shulman RS, Chase JM. Increasing isolation reduces predator: prey species richness ratios in aquatic food webs. Oikos. 2007:116(9):1581-7.

24. Gallardo B, García M, Cabezas Á, González E, González M, Ciancarelli C, Comín FA. Macroinvertebrate patterns along environmental gradients and hydrological connectivity within a regulated river-floodplain. Aquat Sci. 2008:70(3):248-58.

25. Hamer GL, Kitron UD, Goldberg TL, Brawn JD, Loss SR, Ruiz MO, et al. Host selection by Culex pipiens mosquitoes and West Nile virus amplification. Am J Trop Med Hyg. 2009;80(2):268.

26. Estep LK, McClure CJ, Burkett-Cadena ND, Hassan HK, Hicks TL, Unnasch TR, Hill GE. A multi-year study of mosquito feeding patterns on avian hosts in a southeastern focus of eastern equine encephalitis virus. Am J Trop Med Hyg. 2011;84(5):718-26.

27. Ezenwa VO, Milheim LE, Coffey MF, Godsey MS, King RJ, Guptill SC. Land cover variation and West Nile virus prevalence: patterns, processes, and implications for disease control. Vector Borne Zoonot. 2007;7(2):173-80

28. Johnson BJ, Munafo K, Shappell L, Tsipoura N, Robson M, Ehrenfeld J, Sukhdeo MV. The roles of mosquito and bird communities on the prevalence of West Nile virus in urban wetland and residential habitats. Urban Ecosyst. 2012;15(3):513-31.

29. Ma Z, Cai Y, Li B, Chen J. Managing wetland habitats for waterbirds: an international perspective. Wetlands. 2010;30(1):15-27.

30. Shaman J, Day JF, Stieglitz M. Drought-induced amplification and epidemic transmission of West Nile virus in southern Florida. J Med Entomol. 2005;42(2):134-41.

31. Shaman J, Day JF, Stieglitz M. The spatial-temporal distribution of drought, wetting, and human cases of St. Louis encephalitis in southcentral Florida. Am J Trop Med Hyg. 2004;71(3):251-61.

32. Shaman J, Day JF, Stieglitz M. St. Louis encephalitis virus in wild birds during the 1990 south Florida epidemic: the importance of drought, wetting conditions, and the emergence of Culex nigripalpus (Diptera: Culicidae) to arboviral amplification and transmission. J Med Entomol. 2003;40(4):547-54.

33. Shaman J, Day JF, Stieglitz M. Drought-induced amplification of Saint Louis encephalitis virus. Florida Emerg Infect Dis. 2002;8(6):575-80.

34. Skaff NK, Cheruvelil KS. Fine-scale wetland features mediate vector and climate-dependent macroscale patterns in human West Nile virus incidence. Landsc Ecol. 2016;31(7):1615-28.
35. State of Connecticut Mosquito Trapping and Arbovirus Testing ProgramHistorical Information. http://www.ct.gov/caes/cwp/view.asp?a=2819\&q= 552822. Accessed 20 January 2017.

36. Andreadis TG, Anderson JF, Vossbrinck CR, Main AJ. Epidemiology of West Nile virus in Connecticut: a five-year analysis of mosquito data 1999-2003. Vector Borne Zoonot. 2004;4(4):360-78.

37. State of Connecticut Mosquito Trapping and Arbovirus Testing Program. http://www.ct.gov/caes/cwp/view.asp?Q=377446\&A=2819. Accessed 20 January 2017.

38. Reiter P. A portable battery-powered trap for collecting gravid Culex mosquitoes. Mosq News. 1983;43(4):496-8.

39. Soranno PA, Bissell EG, Cheruvelil KS, Christel ST, Collins SM, Fergus CE, et al. Building a multi-scaled geospatial temporal ecology database from disparate data sources: fostering open science and data reuse. Gigascience. 2015:4(1):1-15.

40. Soranno PA, Bacon LC, Beauchene M, Bednar KE, Bissell EG, Boudreau CK, et al. LAGOS-NE: a multi-scaled geospatial and temporal database of lake ecological context and water quality for thousands of U.S. lakes. Gigascience. (In press)

41. National wetland inventory. United States Fish and Wildlife Service, 2014. http://www.fws.gov/wetlands/. Accessed 22 April 2016.

42. ArcGIS Toolbox for Landscape Limnology. https://github.com/cont-limno/ LAGOS_GIS_Toolbox. Accessed 30 August 2015.

43. National hydrography dataset. United States Geological Survey, 2013. http://nhd.usgs.gov/. Accessed 30 August 2015.

44. Xian G, Homer C, Dewitz J, Fry J, Hossain N, Wickham J. Change of impervious surface area between 2001 and 2006 in the conterminous United States. Photogramm Eng Remote Sensing. 2011;77(8):758-62.

45. National climate data center. National Oceanographic and Atmospheric Administration, 2014. http://www1.ncdc.noaa.gov/pub/data/cirs/drd/. Accessed 30 August 2015.

46. Bradter U, Kunin WE, Altringham JD, Thom TJ, Benton TG. Identifying appropriate spatial scales of predictors in species distribution models with the random forest algorithm. Methods Ecol Evol. 2013;4(2):167-74.

47. Nau R. Statistical forecasting: notes on regression and time series analysis: Duke University; 2015. http://people.duke.edu/ rnau/regstep.htm. Accessed 30 August 2015

48. Wood S. Generalized additive models: an introduction with R: Boca Raton: CRC press; 2006

49. Hastie TJ, Tibshirani RJ. Generalized additive models: Boca Raton: Chapman \& Hall/CRC press; 1990

50. Calabrese R, Osmetti SA. Improving forecast of binary rare events data: a GAM-based approach. J Forecasting. 2015;34(3):230-9.

51. Chaves LF, Pascual M. Comparing models for early warning systems of neglected tropical diseases. PLoS Negl Trop Dis. 2007;1(1):e33.

52. Generalized Additive Model Selection. https://stat.ethz.ch/R-manual/R-devel/ library/mgcv/html/gam.selection.html. Accessed 22 April 2016.

53. Dev.expl.mgcv package. GitHub Repository [https://github.com/nskaff/dev. expl.mgcv], 2017.

54. Nasci RS, Edman JD. Culiseta melanura (Diptera: Culicidae): population structure and nectar feeding in a freshwater swamp and surrounding areas in southeastern Massachusetts, USA. J Med Entomol. 1984;21(5):567-72.

55. Howard J, White D, Muller S. Mark-recapture studies on the Culiseta (Diptera: Culicidae) vectors of eastern equine encephalitis virus. J Med Entomol. 1989;26(3):190-9.

56. Molaei G, Oliver J, Andreadis TG, Armstrong PM, Howard JJ. Molecular identification of blood-meal sources in Culiseta melanura and Culiseta morsitans from an endemic focus of eastern equine encephalitis virus in New York. Am J Trop Med Hyg. 2006;75(6):1140-7.

57. Dyer M, Pinowski J, Pinowska B. Granivorous birds in ecosystems: their evolution, populations, energetics, adaptations, impact and control. In: Pinowski J, Kendeigh SC, editors. 3. Population dynamics, vol. 12; 1977. p. 53.

58. Bennett WA. Scale of investigation and the detection of competition: an example from the house sparrow and house finch introductions in North America. Am Nat. 1990:725-47.

59. Haas CA. Dispersal and use of corridors by birds in wooded patches on an agricultural landscape. Conserv Biol. 1995;9(4):845-54.

60. Whittaker KA, Marzluff JM. Species-specific survival and relative habitat use in an urban landscape during the postfledging period. Auk. 2009;126(2):288-99. 
61. Wallis R, Howard J, Main A, Frazier C, Hayes C. Increase of Culiseta malanura coinciding with an epizootic of eastern equine encephalitis in Connecticut. Mosq News. 1974;34(1):63:65.

62. Martin TE. Food as a limit on breeding birds: a life-history perspective. Annu Rev Ecol Evol Syst. 1987;18(1):453-87.

63. Kwan $\mathrm{J}$, Kluh S, Reisen WK. Antecedent avian immunity limits tangential transmission of West Nile virus to humans. PLoS One. 2012;7(3):1-10.

64. Rotenberry JT, Wiens JA. Reproductive biology of shrubsteppe passerine birds: geographical and temporal variation in clutch size, brood size, and fledging success. Condor. 1989;91(1):1-14.

65. Sæther B-E, Sutherland WJ, Engen S. Climate influences on avian population dynamics. Adv Ecol Res. 2004;35:185-209.

66. Robinson RA, Baillie SR, Crick HQ. Weather-dependent survival: implications of climate change for passerine population processes. Ibis. 2007;149(2):357-64.

67. Öberg M, Arlt D, Pärt T, Laugen AT, Eggers S, Low M. Rainfall during parental care reduces reproductive and survival components of fitness in a passerine bird. Ecol Evol. 2015;5(2):345-56.

68. Wickham JD, Stehman SV, Gass L, Dewitz J, Fry JA, Wade TG. Accuracy assessment of NLCD 2006 land cover and impervious surface. Remote Sens Environ. 2013;130:294-304

Submit your next manuscript to BioMed Central and we will help you at every step:

- We accept pre-submission inquiries

- Our selector tool helps you to find the most relevant journal

- We provide round the clock customer support

- Convenient online submission

- Thorough peer review

- Inclusion in PubMed and all major indexing services

- Maximum visibility for your research

Submit your manuscript at www.biomedcentral.com/submit
Biomed Central 